Pacific Journal of Mathematics

LIPCHITZ SPACES 


\title{
LIPSCHITZ SPACES
}

\author{
JERRY A. JOHNSON
}

If $(S, d)$ is a metric space and $0<\alpha<1, \operatorname{Lip}\left(S, d^{\alpha}\right)$ is the Banach space of real or complex-valued functions $f$ on $S$ such that $\|f\|=\max \left(\|f\|_{\infty},\|f\|_{d^{\alpha}}\right)<\infty$, where $\|f\|_{d^{\alpha}}=\sup \{\| f(s)-$ $\left.f(t) \mid d^{-\alpha}(s, t): s \neq t\right\}$. The closed subspace of functions $f$ such that $\lim _{d(s, t) \rightarrow 0}|f(s)-f(t)| d^{-\alpha}(s, t)=0$ is denoted by lip $\left(S, d^{\alpha}\right)$. The main result is that, when inf $s \neq t \quad d(s, t)=0$ lip $\left(S, d^{\alpha}\right)$ contains a complemented subspace isomorphic with $c_{0}$ and $\operatorname{Lip}(S, d)$ contains a subspace isomorphic with $l_{\infty}$. From the construction, it follows that lip $\left(S, d^{\alpha}\right)$ is not isomorphic to a dual space nor is it complemented in $\operatorname{Lip}\left(S, d^{\alpha}\right)$.

If $E$ is a normed space, $E^{*}$ denotes its dual. $c_{0}, l_{1}$, and $l_{\infty}$ denote the usual sequence spaces; "isomorphism" means "linear homeomorphism"; "projection" means "continuous projection"; and $F$ is a complemented subspace of $E$ if there is a projection of $E$ on $F$.

In recent years, much work has been done on the Banach space properties (isomorphic and isometric) of Lipschitz functions. Some of the main references are [1], [2], [3], [4], [10], [11], and [12]. There are still many outstanding conjectures concerning these spaces, some of which seem to be fairly difficult; especially certain questions about extreme points. The known results along these lines can be found in [2], [3], [4], [10], and [11].

It is established in [1] that if $(S, d)$ is an infinite compact subset of Euclidean space, then $\operatorname{lip}\left(S, d^{\alpha}\right)(0<\alpha<1)$ is isomorphic with $c_{0}$ and $\operatorname{Lip}\left(S, d^{\alpha}\right)$ is isomorphic with $l_{\infty}$. The proof given in [1] is not evidently adaptable to arbitrary compact metric spaces. Thus, many of the natural conjectures one might make concerning properties that Lipschitz spaces may share with these sequence spaces are still unresolved. Of course the main one is whether lip $\left(S, d^{\alpha}\right)$ with $0<$ $\alpha<1$ and $S$ compact and infinite is isomorphic with $c_{0}$.

It is shown in [1, Remark, p. 319] that for $(S, d)$ compact and $0<\alpha<1, \operatorname{lip}\left(S, d^{\alpha}\right)$ and $\operatorname{Lip}\left(S, d^{\alpha}\right)$ are isomorphic to subspaces of $c_{0}$ and $l_{\infty}$ respectively. (Although the sketch of the proof given there is not precisely right, Professor Frampton, in a private communication, has exhibited a correct one for which we thank him.) It is well known that an infinite dimensional subspace $A$ of $c_{0}$ contains a subspace $B$ isomorphic to $c_{0}$ and that, since $A$ is separable, $B$ is complemented. In $\S 1$ of this paper, we show that lip $\left(S, d^{\alpha}\right), 0<$ $\alpha<1$, contains a complemented subspace isomorphic to $c_{0}$ when $\inf \{d(s, t): s \neq t\}=0$ (Theorem 1). It is also shown that $\operatorname{lip}\left(S, d^{\alpha}\right)$ is separable if and only if $(S, d)$ is precompact (Theorem 2). (Let us 
remark here that if $(\bar{S}, d)$ is the completion of $(S, d)$ then the restriction map is an isometric isomorphism of $\operatorname{Lip}\left(\bar{S}, d^{\alpha}\right)$ onto $\operatorname{Lip}\left(S, d^{\alpha}\right)$ which sends $\operatorname{lip}\left(\bar{S}, d^{\alpha}\right)$ onto $\operatorname{lip}\left(S, d^{\alpha}\right)(0<\alpha \leqq 1)$.)

In addition, we show in Theorem 1 that for any infinite metric space $(S, d)$ and $0<\alpha \leqq 1, \operatorname{Lip}\left(S, d^{\alpha}\right)$ contains a subspace isomorphic to $l_{\infty}$.

In $\S 2$, we discuss some open problems concerning the isomorphic types of the Lipschitz spaces.

In $\S 3$, we consider some questions about the extreme points of the unit ball and dual unit ball of these spaces.

1. In this section we prove our main theorems. We begin by stating

THEOREM 1. Let $(S, d)$ be a metric space with inf $\{d(s, t): s \neq t\}=0$. Then $\operatorname{Lip}(S, d)$ contains a subspace isomorphic to $l_{\infty}$ and $\operatorname{lip}\left(S, d^{\alpha}\right)$, $0<\alpha<1$, contains a complemented subspace isomorphic to $c_{0}$.

REMARK 1. Theorem 1 has been announced in [5] along with Corollaries 1 and 2 below. It is pointed out in [4, Lemma 2.5] that if $\inf \{d(s, t): s \neq t\}>0$, then both $\operatorname{lip}\left(S, d^{\alpha}\right)$ and $\operatorname{Lip}\left(S, d^{\alpha}\right)$ are isomorphic with the bounded functions on $S$.

The next two corollaries are immediate. We assume $(S, d)$ and $\alpha$ are as in Theorem 1.

CoRollary 1. lip $\left(S, d^{\alpha}\right)$ is not isomorphic with a dual space.

Proof. It has been observed in [7, p. 16] by Lindenstrauss (and is not hard to see) that if a Banach space is complemented in some dual space, it is complemented in its second dual. Hence, if $\operatorname{lip}\left(S, d^{\alpha}\right)$ is isomorphic with a dual space, $c_{0}$ is complemented in $l_{\infty} \cdots a$ contradiction.

Corollary 2. $\operatorname{lip}\left(S, d^{\alpha}\right)$ is not complemented in Lip $\left(S, d^{\alpha}\right)$.

Proof. Let $E$ and $E_{0}$ denote the subspaces isomorphic with $l_{\infty}$ and $c_{0}$ respectively. In the proof of Theorem $1, E$ and $E_{0}$ are constructed so that $E_{0} \subset E$. Let $P$ be a projection of $\operatorname{lip}\left(S, d^{\alpha}\right)$ on $E_{0}$ and suppose $Q$ is a projection of $\operatorname{Lip}\left(S, d^{\alpha}\right)$ on $\operatorname{lip}\left(S, d^{\alpha}\right)$. It is then easy to see that $P Q$ restricted to $E$ is a projection of $E$ onto $E_{0}$. This is a contradiction.

REMARK 2. The theorem also implies the author's result [4, Theorem 2.6]. 
REMARK $3 . l_{\infty}$ is complemented in any Banach space containing it. The following notation is used throughout:

$$
(S, d) \text { is a metric space, }
$$

$$
\bar{B}(s, r)=\{t \in S \mid d(s, t) \leqq r\}
$$

and

$$
\stackrel{\circ}{B}(s, r)=\{t \in S \mid d(s, t)<r\} .
$$

If $A \subset S$ and $B \subset S, d(A, B)=\inf \{d(s, t) \mid s \in A, t \in B\} . \quad d(A,\{t\})$ is denoted by $d(A, t)$.

In [5], we sketched the proof of Theorem 1 in the case where $S$ has no nonconstant Cauchy sequences. We present here the proof where $S$ is assumed to have a limit point. (Recall that completeness may be assumed without loss of generality.) Since the case $\alpha=1$ for $\operatorname{Lip}\left(S, d^{\alpha}\right)$ is similar to the discrete case appearing in [5], we will omit it.

Proof of the Theorem. We begin by constructing a sequence of closed balls that will serve as supports for certain functions.

Let $s_{0}$ be a fixed limit point of $S$. Choose $s_{1} \in S$ with $0<d\left(s_{1}, s_{0}\right)$ and define $r_{1}=(1 / 2) d\left(s_{1}, s_{0}\right), B_{1}=\bar{B}\left(s_{1}, r_{1}\right)$ and $p_{1}=d\left(s_{0}, B_{1}\right)$. Now, assume that $s_{j}(j \geqq 1)$ has been chosen such that $d\left(s_{j}, s_{0}\right)>0$. Set $r_{j}=(1 / 2) d\left(s_{j}, s_{0}\right), B_{j}=\bar{B}\left(s_{j}, r_{j}\right)$ and $p_{j}=d\left(s_{0}, B_{j}\right)$. We first note that

$$
r_{j} \leqq p_{j} \text {. }
$$

Proof. Otherwise, there is a point $t \in B_{j}$ with $d\left(s_{0}, t\right)<r_{j}$. Hence, $d\left(s_{0}, s_{j}\right) \leqq d\left(s_{0}, t\right)+d\left(t, s_{j}\right)<2 r_{j}$, a contradiction.

Now, $p_{j}>0$ implies that there is a point $s_{j+1}$ with $0<d\left(s_{j+1}, s_{0}\right)<$ $(1 / 6) p_{j}$. Set $r_{j+1}=(1 / 2) d\left(s_{j+1}, s_{0}\right), B_{j+1}=\bar{B}\left(s_{j+1}, r_{j+1}\right)$, and $p_{j+1}=d\left(B_{j+1}, s_{0}\right)$.

We record the following facts concerning our construction which are needed later.

$$
p_{j}<\frac{1}{6} p_{j-1} \text { for each } j
$$

Proof. $\quad p_{j} \leqq d\left(s_{0}, s_{j}\right)<(1 / 6) p_{j-1}$.

$$
B_{j} \subset \stackrel{\circ}{B}\left(s_{0}, \frac{1}{2} p_{j-1}\right) \text { for each } j \text {. }
$$

Proof. Let $t \in B_{j}$. Then $d\left(t, s_{0}\right) \leqq d\left(t, s_{j}\right)+d\left(s_{j}, s_{0}\right) \leqq r_{j}+2 r_{j} \leqq$ $3 p_{j}<(1 / 2) p_{j-1}$ by (1) and (2).

$$
\text { If } j>i, \quad d\left(B_{i}, B_{j}\right) \geqq \frac{1}{2} p_{i} .
$$


Proof. If $s \in B_{i}, d\left(s, s_{0}\right) \geqq p_{i}$. If $t \in B_{j}, d\left(t, s_{0}\right)<(1 / 2) p_{j-1} \leqq(1 / 2) p_{i}$ by (3) and (2). Hence, $d(s, t) \geqq d\left(s, s_{0}\right)-d\left(s_{0}, t\right) \geqq(1 / 2) p_{i}$.

$$
d\left(s, \widetilde{B}_{j}\right) \leqq 3 p_{j} \text { for each } j \text { and each } s \in S,
$$
where $\widetilde{B}_{j}$ denotes the complement of $B_{j}$.

Proof. Assume $s \in B_{j}$ since the assertion is otherwise trivial. Given $\varepsilon>0$, there is $t \in B_{j}$ such that $d\left(t, s_{0}\right)<\varepsilon+d\left(B_{j}, s_{0}\right)=\varepsilon+p_{j}$. Thus, $d\left(s, \widetilde{B}_{j}\right) \leqq d\left(s, s_{0}\right) \leqq d\left(s, s_{j}\right)+d\left(s_{j}, t\right)+d\left(t, s_{0}\right) \leqq r_{j}+r_{j}+\varepsilon+p_{j} \leqq$ $3 p_{j}+\varepsilon$, and the assertion follows.

If $s \in B_{i}$ and $t \in B_{j}$ with $j>i$, then

$$
\frac{d\left(s, \widetilde{B}_{i}\right)+d\left(t, \widetilde{B}_{j}\right)}{d\left(B_{i}, B_{j}\right)}<7 .
$$

Proof. By (5) and (4),

$$
\frac{d\left(s, \widetilde{B}_{i}\right)+d\left(t, \widetilde{B}_{j}\right)}{d\left(B_{i}, B_{j}\right)} \leqq \frac{3 p_{i}+3 p_{j}}{(1 / 2) p_{i}}=6\left[1+\frac{p_{j}}{p_{i}}\right] .
$$

Since $j>i, p_{j}<(1 / 6) p_{j-i} \leqq(1 / 6) p_{i}$. Hence, the assertion follows.

We next proceed to construct the isomorphism. We will assume in the proof that for each $j, d\left(s, \widetilde{B}_{j}\right) \leqq 1$ for all $s \in S$ and $d(s, t) \leqq 1$ for all $s, t \in B_{j}$. This clearly can be done by taking $j$ large enough (see (5) and (1)).

First choose a sequence $\left\{\beta_{j}\right\}$ converging to $\alpha$ such that $\alpha<\beta_{j}<1$, $r_{j}^{\beta^{j-\alpha}} \geqq 1 / 2$, and $d^{\beta^{-\alpha}}\left(s_{j}, \widetilde{B}_{j}\right) \geqq 1 / 2$ for each $j$. Now, define $f_{j}(s)=$ $d^{\beta j}\left(s, \widetilde{B}_{j}\right)$ for each $j$ and $s \in S$. Then, given $a=\left\{a_{j}\right\} \in l_{\infty}$, define

$$
f_{a}=\sum_{j=1}^{\infty} a_{j} f_{j} .
$$

It is easy to see that, since the nonzero functions $f_{j}$ have disjoint supports $B_{j}$, the function $f_{a}$ is well-defined and the mapping $a \rightarrow f_{a}$ is one-to-one and linear.

Next, let us note that

$$
\left\|f_{a}\right\| \geqq \frac{1}{2^{1+\alpha}}\|a\|
$$

for each $a \in l_{\infty}$. To see this, observe that for each $j$,

$$
\begin{aligned}
\left\|f_{a}\right\|_{d^{\alpha}} & \geqq \frac{\left|f_{a}\left(s_{j}\right)-f_{a}\left(s_{0}\right)\right|}{d^{\alpha}\left(s_{j}, s_{0}\right)}=\frac{\left|a_{j}\right| d^{\beta} j\left(s_{j}, \widetilde{B}_{j}\right)}{d^{\alpha}\left(s_{j}, s_{0}\right)} \\
& =\frac{\left|a_{j}\right| d^{\beta j}\left(s_{j}, \widetilde{B}_{j}\right)}{\left(2 r_{j}\right)^{\alpha}} \geqq \frac{\left|a_{j}\right| r_{j}^{\beta} \beta_{j}}{2^{\alpha} r_{j}^{\alpha}} \geqq \frac{\left|a_{j}\right|}{2^{1+\alpha}}
\end{aligned}
$$

by our choice of $\beta_{j}$. Since $j$ was arbitrary, the desired inequality follows. 
Now, we will show that $a \rightarrow f_{a}$ is bounded and that $f_{a} \in \operatorname{lip}\left(S, d^{\alpha}\right)$ when $a \in c_{0}$. The boundedness of $a \rightarrow f_{a}$ will show that $f_{a}$ is in fact in $\operatorname{Lip}\left(S, d^{\alpha}\right)$.

In what follows, assume that $a \in l_{\infty}$ is fixed with $\left|a_{j}\right| \leqq 1$ for each $j$ and set $f=f_{a}$. First note that

$$
\|f\|_{\infty}=\sup _{n}\left\|a_{n} f_{n}\right\|_{\infty} \leqq \sup _{n}\left|a_{n}\right| \leqq 1 .
$$

We next proceed to show that $\|f\|_{d^{\alpha}} \leqq 7^{\alpha} \cdot 2^{1-\alpha} \leqq 7$.

Let $s \in S, t \in S, s \neq t$. If $s \in B_{\imath}$ and

$$
t \notin \bigcup_{j=1}^{\infty} B_{j},
$$

then

$$
\frac{|f(s)-f(t)|}{d^{\alpha}(s, t)}=\frac{\left|a_{2}\right| d^{\beta i}\left(s, \widetilde{B}_{i}\right)}{d^{\alpha}(s, t)} \leqq\left|a_{i}\right| d^{\beta i-\alpha}\left(s, \widetilde{B}_{i}\right) \leqq 1,
$$

while if $t \in B_{i}$, then

$$
\frac{|f(s)-f(t)|}{d^{\alpha}(s, t)} \leqq\left|a_{i}\right| d^{\beta_{i}-\alpha}(s, t) \leqq 1 .
$$

Thus, suppose $s \in B_{i}, t \in B_{j}$ and $j>i$. Then

$$
\begin{aligned}
\frac{|f(s)-f(t)|}{d^{\alpha}(s, t)} & \leqq \frac{|f(s)|+|f(t)|}{d^{\alpha}(s, t)} \leqq \frac{d^{\beta i}\left(s, \widetilde{B}_{\imath}\right)+d^{\beta} j\left(t, \widetilde{B}_{j}\right)}{d^{\alpha}\left(B_{i}, B_{j}\right)} \\
& \leqq \frac{d^{\alpha}\left(s, \widetilde{B}_{i}\right)+d^{\alpha}\left(t, \widetilde{B}_{j}\right)}{d^{\alpha}\left(B_{i}, B_{j}\right)},
\end{aligned}
$$

since $\beta_{i}, \beta_{j}>\alpha$ and $d\left(s, \widetilde{B}_{k}\right) \leqq 1$ for all $k$. Now, the last quotient does not exceed

$$
2^{1-a}\left[\frac{d\left(s, \widetilde{B}_{\imath}\right)+d\left(t, \widetilde{B}_{j}\right)}{d\left(B_{\imath}, B_{j}\right)}\right]^{a}
$$

since

$$
\frac{p^{\alpha}+q^{\alpha}}{2} \leqq\left(\frac{p+q}{2}\right)^{\alpha}
$$

for $p \geqq 0, q \geqq 0$. Hence, from (6) above,

$$
\|f\|_{d^{\alpha}} \leqq 1 \vee 7^{\alpha} \cdot 2^{1-\alpha} \leqq 7^{\alpha} \cdot 2^{1-\alpha} \leqq 7 .
$$

Thus, $\left\{f_{a} \mid a \in l_{\infty}\right\}$ is isomorphic with $l_{\infty}$.

Next, let $a \in c_{0},\|a\| \leqq 1$, and let $\varepsilon>0$ be given. We must find $\delta>0$ so that $0<d(s, t)<\delta$ implies that

$$
\frac{|f(s)-f(t)|}{d^{\alpha}(s, t)} \leqq \varepsilon .
$$


Since $a \in c_{0}$, there is a number $N$ such that $n \geqq N$ implies $\left|a_{n}\right|<$ $(1 / 14) \varepsilon$. There exists a $\delta_{0}>0$ such that if $i \neq j$ and $d\left(B_{i}, B_{j}\right)<\delta_{0}$, then $i \geqq N$ and $j \geqq N$. This follows from (4) above. Having chosen $N$, take $0<\delta<\min \left\{\varepsilon^{1 / \beta_{j}-\alpha} \mid 1 \leqq j<N\right\}$ and $\delta<\delta_{0}$. Then $0<$ $d\left(B_{i}, B_{j}\right)<\delta$ still implies $i, j \geqq N$.

Now, let $0<d(s, t)<\delta$. Suppose $s \in B_{i}$ and $t \notin \mathbf{U}_{j \neq i} B_{j}$. If $i<N$, then

$$
\frac{|f(s)-f(t)|}{d^{\alpha}(s, t)} \leqq\left|a_{i}\right| d^{\beta_{i}-\alpha}(s, t) \leqq \delta^{\beta_{i}-\alpha} \leqq \varepsilon .
$$

If $i \geqq N,\left|a_{i}\right| d^{\beta_{i}-\alpha}(s, t) \leqq\left|a_{i}\right| \delta^{\beta_{i}-\alpha} \leqq\left|a_{i}\right|<\varepsilon / 14<\varepsilon$. Next, suppose $s \in B_{\imath}$ and $t \in B_{j}(j>i)$. Then

$$
\begin{aligned}
\frac{|f(s)-f(t)|}{d^{\alpha}(s, t)} & \leqq \frac{\left|a_{i}\right| f_{i}(s)+\left|a_{j}\right| f_{j}(t)}{d^{\alpha}(s, t)} \\
& \leqq\left(\left|a_{i}\right|+\left|a_{j}\right|\right) \frac{d^{\beta_{i}}\left(s, \widetilde{B}_{i}\right)+d^{\beta j}\left(t, \widetilde{B}_{j}\right)}{d^{\alpha}(s, t)} \\
& \leqq\left(\frac{\varepsilon}{14}+\frac{\varepsilon}{14}\right) \cdot 7=\varepsilon ;
\end{aligned}
$$

this is because $0<d(s, t)<\delta, s \in B_{i}$ and $t \in B_{j}$ imply $d\left(B_{i}, B_{j}\right)<\delta$ and hence $i, j \geqq N$.

The only part now remaining is to show that " $c_{0}$ " is complemented in $\operatorname{lip}\left(S, d^{\alpha}\right)$. Our proof will entail the construction of a projection of $\operatorname{Lip}\left(S, d^{\alpha}\right)$ onto the image of $l_{\infty}$ which sends lip $\left(S, d^{\alpha}\right)$ onto the image of $c_{0}$. As mentioned before, since $l_{\infty}$ is injective, it is already known that it must be complemented in $\operatorname{Lip}\left(S, d^{\alpha}\right)$.

Given $f \in \operatorname{Lip}\left(S, d^{\alpha}\right)$, define

$$
P f=\sum_{n} a_{n} f_{n}
$$

where

$$
a_{n}=\frac{f\left(s_{n}\right)-f\left(s_{0}\right)}{f_{n}\left(s_{n}\right)} .
$$

It is easy to see that $P$ is linear and that $P^{2}=P$. Let $\|f\| \leqq 1$. We must first find a constant $M$ such than $\left|a_{n}\right| \leqq M$ for each $n$. $d\left(s_{n}, s_{0}\right)=2 r_{n}$, for each $n$, by definition; thus,

$$
d^{\alpha}\left(s_{n}, s_{0}\right)=2^{\alpha} r_{n}^{\alpha} \leqq 2^{\alpha} d^{\alpha}\left(s_{n}, \widetilde{B}_{n}\right) \leqq 2^{1+\alpha} d^{\beta_{n}}\left(s_{n}, \widetilde{B}_{n}\right)
$$

for each $n$, since $\beta_{n}-\alpha$ was chosen small enough so that

$$
d^{\beta_{n}-\alpha}\left(s_{n}, \widetilde{B}_{n}\right) \geqq \frac{1}{2}
$$

Hence, 


$$
\left|f\left(s_{n}\right)-f\left(s_{0}\right)\right| \leqq d^{\alpha}\left(s_{n}, s_{0}\right) \leqq 2^{1+\alpha} d^{\beta n}\left(s_{n}, \widetilde{B}_{n}\right)=2^{1+\alpha} f_{n}\left(s_{n}\right)
$$

for each $n$. Therefore, $\left|a_{n}\right| \leqq 2^{1+\alpha}$ when $\|f\| \leqq 1$.

Now, let $f \in \operatorname{lip}\left(S, d^{\alpha}\right)$. We must show that

$$
\lim _{n \rightarrow \infty} \frac{\left|f\left(s_{n}\right)-f\left(s_{0}\right)\right|}{f_{n}\left(s_{n}\right)}=0 .
$$

As above, we have $d^{\alpha}\left(s_{n}, s_{0}\right) \leqq 2^{1+\alpha} f_{n}\left(s_{n}\right)$, so

$$
\lim _{n \rightarrow \infty} \frac{\left|f\left(s_{n}\right)-f\left(s_{0}\right)\right|}{f_{n}\left(s_{n}\right)} \leqq 2^{1+\alpha} \lim _{n \rightarrow \infty} \frac{\left|f\left(s_{n}\right)-f\left(s_{0}\right)\right|}{d^{\alpha}\left(s_{n}, s_{0}\right)}=0 .
$$

This completes the proof of the theorem.

We close this section with Theorem 2 which answers a question raised in [5].

THEOREM 2. The following are equivalent for $0<\alpha<1$.

(a) $(S, d)$ is precompact.

(b) $\operatorname{lip}\left(S, d^{\alpha}\right)^{*}$ is separable.

(c) $\operatorname{lip}\left(S, d^{\alpha}\right)$ is separable.

Proof. In [3] Jenkins showed that if $(S, d)$ is compact, the span of the point evaluations is dense in $\operatorname{lip}\left(S, d^{\alpha}\right)^{*}$. It is clear that $\left\|\varepsilon_{s}-\varepsilon_{t}\right\| \leqq d^{\alpha}(s, t)$, where $\varepsilon_{s}(f)=f(s)$. Thus, $\left\{\varepsilon_{s} \mid s \in S\right\}$, and hence lip $\left(S, d^{\alpha}\right)^{*}$, is separable. (See [4] for further discussion.) Thus (a) $\Rightarrow(b)$.

(b) $\Rightarrow$ (c) is true for any Banach space, so assume (a) fails. Then there exists a sequence $\left\{s_{n}\right\} \subset S$ and a number $p>0$ such that $d\left(s_{n}, s_{m}\right) \geqq p$ for each $n \neq m$. Let $\left\{s_{n_{k}}\right\}$ be any subsequence of $\left\{s_{n}\right\}$ and let $A=\left\{s_{n_{2 k+1}}\right\}$. Now, the function $f$ defined by $f(s)=\min \{d(s, A), 1\}$ is an element of $\operatorname{lip}\left(S, d^{\alpha}\right)$, where $d(s, A)=\inf \{d(s, t) \mid t \in A\}$. However, $f\left(s_{n_{2 k}}\right) \geqq \min (p, 1)>0$ for each $k$, while $f\left(s_{n_{2 k+1}}\right)=0$ for each $k$. Thus, $\lim _{k} f\left(s_{n_{k}}\right)=\lim _{k} \varepsilon_{s_{n_{k}}}(f)$ does not exist; i.e., $\left\{\varepsilon_{s_{n}}\right\}$ has no weak*-convergent subsequence. This implies that the dual unit ball of lip $\left(S, d^{\alpha}\right)$ is not $w^{*}$-metrizable, which completes the proof of the proposition by contradicting (c).

2. An investigation of the Banach space properties of the Lipschitz spaces is far from complete, and questions concerning those properties of $\left(S, d^{\alpha}\right)$ that give rise to corresponding properties of the Lipschitz spaces are abundant. The ultimate problem of classifying these spaces as to isomorphic type does not appear easy. Even the following two problems are still open:

If $(S, d)$ is compact and infinite, and $0<\alpha<1$,

(1) is $\operatorname{lip}\left(S, d^{\alpha}\right)$ isomorphic with $c_{0}$ and 
(2) is $\operatorname{Lip}\left(S, d^{\alpha}\right)$ isomorphic with $l_{\infty}$ ?

By [4, Theorem 4.7] it is known that $\operatorname{Lip}\left(S, d^{\alpha}\right)$ is isometrically isomorphic with the bidual of $\operatorname{lip}\left(S, d^{\alpha}\right)$. Hence, a positive answer to (1) yields a positive answer to (2). As we mentioned in the introduction, the best result in this direction appears in [1].

One possible avenue of attack on question (2) may be furnished by the following proposition, since it seems that the problem of showing (b) or (c) may be more tractable than showing (e) directly. (For the definitions of $\mathscr{L}_{1}$ and $\mathscr{L}_{\infty}$ spaces see [9]. A Banach space is injective if it is complemented in every Banach space containing it.)

Proposition 1. Let $(S, d)$ be compact and infinite. If $0<\alpha<1$, the following assertions are equivalent.

(a) $\operatorname{Lip}\left(S, d^{\alpha}\right)$ is injective.

(b) $\operatorname{Lip}\left(S, d^{\alpha}\right)$ is an $\mathscr{L}_{\infty}$ space.

(c) $\operatorname{lip}\left(S, d^{\alpha}\right)$ is an $\mathscr{L}_{\infty}$ space.

(d) $\operatorname{lip}\left(S, d^{\alpha}\right)^{*}$ is an $\mathscr{L}_{1}$ space.

(e) $\operatorname{Lip}\left(S, d^{\alpha}\right)$ is isomorphic with $l_{\infty}$.

(a) and (b) are equivalent even if $\alpha=1$ and $(S, d)$ is arbitrary.

Proof. [9, Remark 2, p. 337] yields (a) $\Leftrightarrow($ b) immediately since $\operatorname{Lip}(S, d)$ is a dual space for any metric space [4]. (a) $\Leftrightarrow(\mathrm{c})$ is [9, Corollary, p. 335]. (d) $\Leftrightarrow$ (b) is [9, Theorem I (iii), p. 327]. (d) $\Leftrightarrow$ (e) is from the observation in [9, Problem 2a, p. 344] and the fact that $\operatorname{lip}\left(S, d^{\alpha}\right)^{*}$ is separable (see [3]).

Although questions (1) and (2) are the most important, the following questions are also open in general.

(3) Does $\operatorname{Lip}(S, d)$ have the approximation property?

(4) If $(S, d)$ is compact and $0<\alpha<1$, do lip $\left(S, d^{\alpha}\right)^{*}$ and $\operatorname{lip}\left(S, d^{\alpha}\right)$ have Schauder bases?

Let us remark that in [3] it was shown that $\operatorname{lip}\left(S, d^{\alpha}\right)^{*}$ is separable.

Added in proof: By Enfio's example, there is a (non-compact) metric space for which $\operatorname{Lip}(S, d)$ fails the approximation property. Using an idea due to Lindenstrauss it can be shown that $\operatorname{Lip}(S, d)$ is not injective if $(S, d)$ is the Hilbert cube.

3. In addition to the questions in $\S 2$ concerning the isomorphism types of the Lipschitz spaces, there are some interesting problems dealing with the extreme points of their unit balls and dual unit balls.

We begin by stating a theorem due to Lindenstrauss and Phelps 
[8, Theorem 3.1]:

(I) If $E$ is a normed space whose dual unit ball has countably many extreme points, then $E^{*}$ is separable and $E$ contains no infinite dimensional reflexive subspaces.

Quite recently William Johnson and Haskell Rosenthal [6] proved:

(II) If $E$ is an infinite dimensional Banach space with $E^{* *}$ separable, then $E$ and $E^{*}$ have infinite dimensional reflexive subspaces.

(The author would like to thank Professors Johnson and Rosenthal for access to a preprint of [6].)

In view of (I), (II) now has as an immediate corollary the following:

(III) The unit ball of $E^{* *}$, for any infinite dimensional Banach space, has uncountably many extreme points.

The aforementioned results have some immediate applications to Lipschitz spaces. We proceed to mention a few.

Since it is known that $\operatorname{Lip}\left(S, d^{\alpha}\right)$ is a second dual space for $0<\alpha<1$ (see [3] and [4]), it follows from (III) that its unit ball has uncountably many extreme points. In view of (I), Theorem 1 and the fact [4, Theorem 4.1] that $\operatorname{Lip}(S, d)$ is a dual space for any metric space, we can state the following:

Proposition 2. If $(S, d)$ is any metric space with $S$ infinite, then the unit ball of Lip $(S, d)$ has uncountable many extreme points.

Of course, since $\operatorname{Lip}(S, d)$ is a dual space, its unit ball is the $w^{*}$-closed convex hull of its extreme points. As shown in [4, Corollary 4.4], convergence of bounded nets in the $w^{*}$-topology coincides with pointwise convergence in general, and with uniform convergence when $(S, d)$ is compact. Thus, in both senses, the unit ball of Lip $(S, d)$ has many extreme points. The problem of characterizing the extreme points of the unit ball of $\operatorname{Lip}(S, d)$ appears to be quite difficult. The only results we know of this kind are in [10] and [11], and these are for $S=[0,1]$. In both papers a proof is given that the unit ball of Lip $[0,1]$ is the norm-closed convex hull of its extreme points. This problem is also open for more general metric spaces.

Assuming $S$ is compact and countable, (II) yields another previously unknown result. Again in [3] the extreme points of the unit ball of Lip $(S, d)^{*}$ are shown to be of two types: one corresponding to a subset of $S \cup[(S \times S) \sim \Delta]$ and the other a set $Q$ "arising from" the Stone-Čech compactification of $(S \times S) \sim \Delta$ (see [3] or [4]). It was shown in [4] that, in general, $Q$ must be nonempty. It now follows from (III) that if $S$ is compact and countably infinite, $Q$ must be uncountable. The work of Sherbert [12] shows that the functionals in $Q$ must be point derivations. However, a complete description of $Q$ still appears difficult. We sum up this result in 
Proposition 3. If $S$ is compact and countably infinite, the set $Q$ of extreme points of the unit ball of $\operatorname{Lip}(S, d)^{*}$ that are point derivations is uncountable.

\section{REFERENCES}

1. R. Bonic, J. Frampton, and A. Tromba, A-Manifolds, J. Functional Analysis, 3 (1969), 310-320.

2. K. deLeeuw, Banach spaces of Lipschitz functions, Studia Math., 21 (1961/62), $55-66$.

3. T. M. Jenkins, Banach spaces of Lipschitz functions on an abstract metric space, Thesis, Yale Univ., New Haven, Conn., 1967.

4. J. A. Johnson, Banach spaces of Lipschitz functions and vector-valued Lipschitz functions, Trans. Amer. Math. Soc., 148 (1970), 147-169.

5. - Lipschitz function spaces for arbitrary metrics, Bull. Amer. Math. Soc., 78 (1972), 702-705,

6. W. B. Johnson and H. P. Rosenthal, On $w^{*}$-basic sequences and their applications to the study of Banach spaces, Studia Math., 43 (1972), 77-92.

7. J. Lindenstrauss, Extentions of compact operators, Memoirs Amer. Math. Soc., 48 (1964).

8. J. Lindenstrauss and R. Phelps, Extreme point properties of convex bodies in reflexive Banach spaces, Israel J. Math., 6 (1968), 39-48.

9. J. Lindenstrauss and H. P. Rosenthal, The $\mathscr{L}_{p}$ spaces, Israel J. Math., 7 (1969), 325-349.

10. N. V. Rao and A. K. Roy, Extreme Lipschitz functions, Math. Ann., 189 (1970), 26-46.

11. A. K. Roy, Extreme points and linear isometries of the Banach space of Lipschitz functions, Canad. J. Math., 20 (1968), 1150-1164.

12. D. R. Sherbert, The structure of ideals and point derivations in Banach algebras of Lipschitz functions, Trans. Amer. Math. Soc., 111 (1964), 240-272.

Received November 29, 1972 and in revised form March 8, 1973. This research was supported in part by a grant from the Oklahoma State University Research Foundation.

OKLahoma State UNIVERSity 


\section{PACIFIC JOURNAL OF MATHEMATICS}

\section{EDITORS}

RICHARD ARENS (Managing Editor)

University of California

Los Angeles, California 90024

R. A. BeAumont

University of Washington

Seattle, Washington 98105
J. DugundJI*

Department of Mathematics

University of Southern California

Los Angeles, California 90007

D. Gilbarg and J. Milgram

Stanford University

Stanford, California 94305

\section{ASSOCIATE EDITORS}

E. F. BECKENBACH

B. H. NEUMANN

F. WOLF

K. YoSHIDA

\section{SUPPORTING INSTITUTIONS}

UNIVERSITY OF BRITISH COLUMBIA
CALIFORNIA INSTITUTE OF TECHNOLOGY
UNIVERSITY OF CALIFORNIA
MONTANA STATE UNIVERSITY
UNIVERSITY OF NEVADA
NEW MEXICO STATE UNIVERSITY
OREGON STATE UNIVERSITY
UNIVERSITY OF OREGON
OSAKA UNIVERSITY

UNIVERSITY OF BRITISH COLUMBIA CALIFORNIA INSTITUTE OF TECHNOLOGY UNIVERSITY OF CALIFORNIA MONTANA STATE UNIVERSITY NEW MEXICO STATE UNIVERSITY UNIVERSITY OF OREGON OSAKA UNIVERSITY
UNIVERSITY OF SOUTHERN CALIFORNIA STANFORD UNIVERSITY UNIVERSITY OF TOKYO UNIVERSITY OF UTAH WASHINGTON STATE UNIVERSITY UNIVERSITY OF WASHINGTON AMERICAN MATHEMATICAL SOCIETY NAVAL WEAPONS CENTER

* C. R. DePrima California Institute of Technology, Pasadena, CA 91109, will replace J. Dugundji until August 1974. 


\section{Pacific Journal of Mathematics}

\section{Vol. 51, No. $1 \quad$ November, 1974}

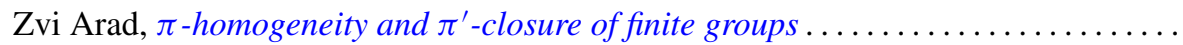

Ivan Baggs, A connected Hausdorff space which is not contained in a maximal

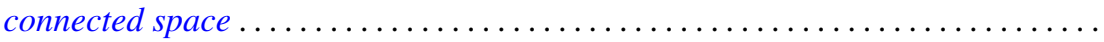

Eric Bedford, The Dirichlet problem for some overdetermined systems on the unit ball in $C^{n}$

R. H. Bing, Woodrow Wilson Bledsoe and R. Daniel Mauldin, Sets generated by

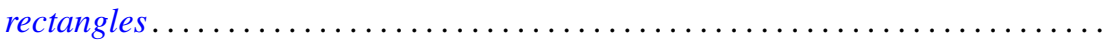

Carlo Cecchini and Alessandro Figà-Talamanca, Projections of uniqueness for

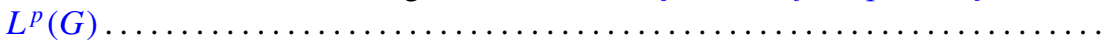

Gokulananda Das and Ram N. Mohapatra, The non absolute Nörlund summability of Fourier series .

Frank Rimi DeMeyer, On separable polynomials over a commutative ring ........ Richard Detmer, Sets which are tame in arcs in $E^{3} \ldots \ldots \ldots \ldots \ldots \ldots \ldots \ldots$

William Erb Dietrich, Ideals in convolution algebras on Abelian groups ..........

Bryce L. Elkins, A Galois theory for linear topological rings .................

William Alan Feldman, A characterization of the topology of compact convergence on $C(X)$.

Hillel Halkin Gershenson, A problem in compact Lie groups and framed cobordism

Samuel R. Gordon, Associators in simple algebras.

Marvin J. Greenberg, Strictly local solutions of Diophantine equations

Jon Craig Helton, Product integrals and inverses in normed rings . . . . . . . . . . . .

Domingo Antonio Herrero, Inner functions under uniform topology . . .

Jerry Alan Johnson, Lipschitz spaces .

Marvin Stanford Keener, Oscillatory solutions and multi-point boundary value

functions for certain nth-order linear ordinary differential equations.

John Cronan Kieffer, A simple proof of the Moy-Perez generalization of the

Shannon-McMillan theorem .......................

Joong Ho Kim, Power invariant rings

Gangaram S. Ladde and V. Lakshmikantham, On flow-invariant sets .

Roger T. Lewis, Oscillation and nonoscillation criteria for some self-adjoint even

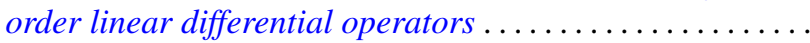

Jürg Thomas Marti, On the existence of support points of solid convex sets ..

John Rowlay Martin, Determining knot types from diagrams of knots . .

James Jerome Metzger, Local ideals in a topological algebra of entire functions

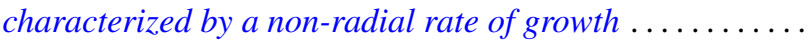

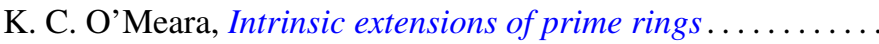

Stanley Poreda, A note on the continuity of best polynomial approximations ..

Robert John Sacker, Asymptotic approach to periodic orbits and local prolongations

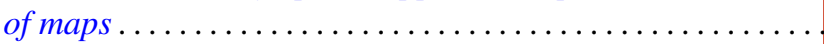

Eric Peter Smith, The Garabedian function of an arbitrary compact set . .

Arne Stray, Pointwise bounded approximation by functions satisfying a side condition

John St. Clair Werth, Jr., Maximal pure subgroups of torsion complete abelian

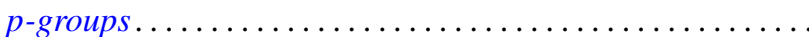

